\title{
Alzheimer's Disease and Oral-Systemic Health: Bidirectional Care Integration Improving Outcomes
}

\author{
Anne O. Rice* \\ Oral Systemic Seminars, Conroe, TX, United States
}

Dentistry is an effective healthcare field that can impact Alzheimer's disease through prevention and education. Every day dental providers use an arsenal of assessment protocols directly coinciding with modifiable Alzheimer's risk factors. An innovative way to help in the prevention of Alzheimer's disease is to utilize oral health professionals who reach the public in ways other health care providers may not. Bidirectional care integration is needed to stifle many systemic diseases and Alzheimer's disease is no different. Ultimately with collaborative care the patient reaps the benefits. Alzheimer's is associated with many etiologies and pathophysiological processes. These include cardiovascular health, smoking, sleep, inflammatory pathogens, and diabetes. In the United States,

OPEN ACCESS

Edited by:

Bei $W u$,

New York University, United States

Reviewed by:

Denis Bourgeois,

Université Claude Bernard Lyon 1,

France

Massimo Petruzzi,

University of Bari Aldo Moro, Italy

*Correspondence:

Anne O. Rice

anneorice@gmail.com

Specialty section:

This article was submitted to

Oral Hygiene and Oral Health Policy,

a section of the journal

Frontiers in Oral Health

Received: 01 March 2021

Accepted: 28 May 2021

Published: 05 July 2021

Citation:

Rice AO (2021) Alzheimer's Disease and Oral-Systemic Health:

Bidirectional Care Integration

Improving Outcomes

Front. Oral. Health 2:674329.

doi: 10.3389/froh.2021.674329 dental providers assess each of these factors daily and can be instrumental in educating patients on the influence of these factors for dementia prevention. Globally, by 2025, the number of people with Alzheimer's disease is expected to rise by at least $14 \%$. Such increases will strain local and national health care systems, but for the US if Medicare were expanded to include dental services, many older adults could be spared needless suffering. The goal of this perspective article is to highlight existing practices being used in the field of dentistry that can easily be adapted to educate patients in preventive care and treat risk factors. It is the duty of healthcare professionals to explore all opportunities to stem the advance of this disease and by integrating oral and systemic health into transdisciplinary science, health care and policy may do just that.

Keywords: Alzheimer's disease, medicare, sleep apnea, smoking, dentistry, pathogens, diabetes, cardiovascular disease

\section{INTRODUCTION}

Alzheimer's disease $(\mathrm{AD})$ is a progressive mental deterioration that occurs in middle or old age due to the brain's degeneration [1]. Every $65 \mathrm{~s}$, someone in the United States is diagnosed with Alzheimer's disease, the most common form of dementia, and it currently affects over 5.8 million people in the United States. The Alzheimer's Association projects by 2050 nearly 15 million people in the United States will receive an Alzheimer's diagnosis. The same report shows that a full half of primary care physicians feel unprepared to meet the demand of such a drastic increase [2]. In 2014, Rush University Medical Center analyzed death records nationally and found that most people who die from Alzheimer's have a recorded cause of death listed as respiratory or cardiac disease. When taking these numbers into account, $\mathrm{AD}$ would be elevated to the third leading cause of death in the United States [3]. 
Hundreds of billions of dollars in research and drug exploration have yielded a $99.6 \%$ drug failure rate [4]. While various drug developers are taking different approaches considering such near complete failure, many scientists and physicians are targeting prevention as the best strategy to reduce Alzheimer's cases [5-10]. In 2017, The Lancet Commission presented a report that stated more than one-third of global dementia cases may be preventable through addressing lifestyle factors that impact a person's risk [11]. The World Health Organization (WHO) agreed with this assessment and strongly recommended physical activity, quitting smoking, managing hypertension, and diabetes to reduce the risk of cognitive decline [12]. Disturbed sleeping patterns and periodontal disease have also been related to $\mathrm{AD}$ and accelerated cognitive decline rates [13-19].

The brain changes from Alzheimer's disease start at least a decade before symptoms show [20, 21], and as stated above, prevention is the best current defense against this disease. Prevention strategies should begin years before the typical onset presents, which is where dental providers can make the most significant contribution. Every day, dental professionals are performing vital tests, giving education on preventative measures, and prescribing medications in the line of treating and preventing dental health concerns that may also serve to reduce the risk of Alzheimer's. If dental professionals can use these routine tests to educate their patients and offer counseling on risk and preventative measures, more ways may be found to reduce the human suffering caused by AD. Even simply good oral health can have a positive effect on brain health [22]. This perspective focuses on the work that dental professionals regularly administer in the areas of cardiovascular health, smoking, sleep, inflammatory pathogens, and diabetes that can also serve in the prevention of Alzheimer's, with a special note on the benefit of Medicare spending in the dental field and Alzheimer's prevention.

\section{HEALTH ISSUES AFFECTING ALZHEIMER'S DISEASE}

\section{Cardiovascular Health}

Many factors related to cardiovascular health increase the risks of Alzheimer's [23, 24]. Midlife obesity, hypertension, and high cholesterol are all associated with an increased risk of dementia [25-27]. A study that followed Americans from 1987 to 2017 revealed that individuals with hypertension in midlife had a significant risk factor for cognitive decline [28]. In a 2014 study, Dr. Gottesman et al. found hypertension was associated with $39 \%$ greater odds of dementia [29]. Another study of over 500 people born the same week in 1946 measured blood pressure, cognitive assessments, and PET imaging at ages 36, 43, 53, 60-64, and 69 years. Results showed that elevated blood pressure in middle age resulted in drastic increases in dementia later in life, smaller brain volume, and increased blood vessel damage [30].

\section{Discussion}

Taking blood pressure is considered standard of care in dentistry. On every patient at every visit blood pressure is taken and recorded, which enables clinicians to see subtle increases that may indicate systemic issues. Dental providers see patients as often as four times more per year than their general practitioners. Panoramic radiographs are taken during regular assessments by most dental practices at initial visits, and every 3-5 years following. The radiographs allow practitioners to see cysts, tumors, wisdom teeth, the temporomandibular joint, and bone abnormalities, including bone loss from periodontal disease. The film can also detect any calcifications in the soft tissue area. Atherosclerotic lesions of the carotid artery occur at the bifurcation of the common carotid. When these lesions are calcified, they may present on panoramic radiographs as nodular calcifications or vertical radiopacities [31]. Often, these issues remain undetected, as they rarely produce symptoms. Ultimately, the interruption of blood flow to the brain causes a loss of neurological function and may lead to an ischemic or hemorrhagic stroke. Stroke is a strong, independent, and potentially modifiable risk factor for all-cause dementia [32]. People who have had a stroke have nearly double the risk of developing Alzheimer's disease [33]. Clinicians should be careful to evaluate panoramic radiographs in patients who have a history of cardiovascular disease, and other risk factors such as smoking, hypercholesteremia, being overweight or having diabetes. Calcifications are also associated with oral infections and increased mortality and clinicians should carefully assess panoramic radiographs to intercept calcified atherosclerotic lesions of the carotid artery [34]. By remaining vigilant while reviewing radiographs, dental professionals can help identify potential risk factors that may be early indicators of Alzheimer's.

\section{Smoking}

Smoking is linked to vascular problems, which is a contributor to Alzheimer's. This may be by way of strokes or smaller brain bleeds, but toxins in cigarette smoke increase oxidative stress and inflammation, which have been linked to Alzheimer's. A 2017 study found that a smoking habit increases the chance of dementia later in life [29]. Studies have found that smokers have reduced brain size, specifically in the cortex, which is responsible for many mental tasks including visual processing and complex abstract thinking [35]. Smoking is a leading cause of preventable death [36], so many smokers may actually die before they reach the age when dementia develops. Therefore, it is difficult for data to be conclusive as to how severely smoking is related to $\mathrm{AD}$, but we know there is a strong correlation [37]. Fortunately, by quitting smoking, damage can at least be partially reversed [36].

\section{Discussion}

Smoking cessation programs within the dental practice are already being done, lending itself to individualized support. Dental practitioners have the availability to follow the 5 A's smoking cessation plan (ask, advise, assess, assist and arrange) developed by the US Public Health Service to enhance motivation for smokers to change their behavior [38]. Whether clinicians refer services, write a prescription, or perhaps even assess current smoking status by measuring exhaled carbon monoxide levels, they have the potential to change the lives of smoking patients. Through support, care, and education dental professionals can 
help to illustrate to patients the dangers of smoking concerning risk of $\mathrm{AD}$.

\section{Sleep}

Sleep is critical to overall wellness $[39,40]$. It helps to refresh the brain, clean out waste products [41], and replenishes nutrients. Impaired sleep effects the glymphatic system, the system that clears the brains waste products, and new research suggest that there may be a causal relationship between inadequate sleep and dementias [42]. Sleep cleans the hippocampus which facilitates consolidation of memories, which is a crucial step in being able to take in and process new information [43]. Getting proper amounts of sleep can help with most systemic ailments, from lowering blood pressure, reducing depression, obesity, regulating blood sugar, and strengthening the immune system. Proper sleep has been shown to increase amyloid clearance from the brain, and new research shows that people getting proper sleep make less amyloid [44-46]. Other studies have found that a lack of deep sleep is associated with higher tau levels, which forms toxic tangles inside brain cells and may be linked to Alzheimer's [47].

Sleep apnea, a condition that happens when the airway becomes blocked or collapses during the night, has been associated with numerous contributory factors for $\operatorname{AD}[48,49]$. According to the American Sleep Apnea Association, about 22 million Americans have sleep apnea [50]. A 2013 study found that older adults who experience fragmented sleep, such as that caused by sleep apnea, are more prone to develop Alzheimer's disease [13].

\section{Discussion}

Dentistry has become a force to help patients with sleep apnea Dental professional's contribution to patient care in this area should include assisting in diagnosing and to referring to other healthcare specialists, and to determining when dental therapies are of value, e.g., and even treating mild to moderate apnea with mandibular advancement devices [51,52]. The collaboration between dentists and sleep physicians is growing stronger by the day. Being able to execute simple questionnaires like the STOP Bang and the Epworth Sleepiness Scale can help identify potential risk factors. Additionally, indicators of sleep disordered breathing, such as a scalloped tongue, large tonsils, a red beaten uvula, or grinding patterns [53], can be noted with a simple cursory look during an oral cancer exam. Two of the quickest and most simple assessments are the Malampatti score and tonsil grading that are incredible evaluators and teaching tools for the patient. Dental professionals are educators and pivotal in the discussion of risks, referrals, and treatment options of disordered sleep, which may help to lower patient's risk of developing Alzheimer's disease [54, 55].

\section{Inflammatory Pathogens}

Compelling active research regarding microbes, the immune system and the oral cavity and their interaction with inflammation keeps periodontal disease at the forefront of systemic discussions [56]. Many studies have shown that older people with periodontal disease may have an increased risk of Alzheimer's [57-59]. Inflammation causes neural damage from the cascade of events of the central nervous system starting with pro-inflammatory cytokines such as C-reactive proteins, tumor necrosis factor-a, interleukin-1 and interleukin-6 [60]. Periodontal pathogens such as Porphyromonas gingivalis, Treponema denticola, Prevotella intermedia, and even HSV1 (cold sores) may all be implicated in Alzheimer's [61-64].

Dr. Judith Miklossy has been studying spirochetes for 3 decades. She was one of the first to demonstrate spirochetes in brain matter. In vivo and in vitro spirochetes were able to reproduce the clinical, pathological and biological hallmarks of AD. These results fulfilled Hill's criteria and confirmed a causal relationship [65]. A 2021 report revealed T. denticola as a potential contributing factor, along with $P$. gingivalis, as risk factors for $\mathrm{AD}$. The research group found that $T$. denticola had the ability to enter the brain and increased the expression of amyloid- $\beta$ (the hallmark in $A D$ ), although the mechanism is unclear [66].

It has been reported that amyloid forms almost instantly around viruses and bacteria, and that infections, including mild ones that produce only minimal symptoms, fire up the immune system in the brain and leave a debris trail that is the hallmark for Alzheimer's $[67,68]$. When a virus or bacterium sneaks past the blood-brain barrier, which becomes leaky with age, the brain's defense system is triggered. To combat the intruder, the brain makes amyloid to act as a sticky web to trap the intruder. The beta-amyloid is an antimicrobial peptide (basically, a protein) that the immune system creates to physically trap germs, so what is left is a webby plaque seen in the brains of those with Alzheimer's [69]. Some Alzheimer's researchers are convinced that microbes are causative in Alzheimer's [70, 71]. P. gingivalis is a high risk, red complex periodontal pathogen [72]. There is increasing evidence implicating the polymicrobial infection with $P$. gingivalis as playing a part in disease pathogenesis, not only from the low-grade inflammation but the actual translocation into the brain vasculature [64]. A link between Alzheimer's and P. gingivalis in the brain is consistent with this emerging model for microbes in the disease's etiology [58, 73-75].

\section{Discussion}

There is mounting evidence of periodontal disease impacting altering, systemic health negatively. There are independent associations between periodontal disease and a host of systemic diseases including but not limited to: diabetes, cardiovascular diseases, certain cancers, and cognitive diseases [76, 77]. The activities in health and disease within the gut, the brain and the oral cavity seem to have overlapping consequences. For example, individuals with chronic local inflammation due to periodontal disease have corresponding changes within the gut, to include a link to inflammatory bowel disease [78]. A growing body of clinical and experimental evidence suggests that gut microbiota may contribute to and influence brain disorders [79].

Treating patient's periodontal disease and preventing future events has long been a goal of dental professionals. The strong evidence that reducing oral inflammation, created by infections of the periodontia, contributes to a reduction in systemic inflammation, reinforces the concept that dental providers have a responsibility to help in treating a patient's total health, which 
in turn may reduce the possibility of many systemic diseases including Alzheimer's. We are the only licensed professionals with this capability, so it is essential to educate ourselves and our patients about Alzheimer's related risks and their periodontal health. Whether they are a causal agent, a contributory agent, or an exacerbator matters not, dentistry helps communities lower their risk. Our tools, from chairside pathogen testing to the use of ozone and lasers, not to be out done by education skills and behavior change strategies, can be put to use in ways to mitigate yet another disease.

\section{Diabetes}

Nearly $36 \%$ of all U.S. adults and $50 \%$ of those 60 years or older are estimated to have metabolic syndrome, a combination of health conditions such as obesity, high blood pressure, insulin resistance, type 2 diabetes, or a poor lipid profile [80]. The correlation between diabetes and risk for Alzheimer's has been the focus of numerous studies [81, 82]. Additionally, there is a new type of diabetes being studied, type 3, which is also strongly correlated with Alzheimer's [83]. People with type 2 diabetes may be twice as likely to develop Alzheimer's, and those with prediabetes or metabolic syndrome may have an increased risk for having predementia or mild cognitive impairment [84]. Those with high blood sugar, whether technically diabetic or not, have a faster cognitive decline rate than those with normal blood sugar [85].

\section{Discussion}

Oral health professionals have long been aware of the complications of hypoglycemia in patients with diabetes. Many oral health professionals scrutinize health histories, question patients, and check their blood glucose levels, yet there is a need to increase the monitoring of diabetes during dental visits. In 2018, the American Dental Association added CDT code D0411 for chairside HbA1c, and in 2019 code D0412 to check blood glucose levels. This was not put in place for the expectation to diagnose diabetes, but to help monitor patients during dental procedures. Chairside screening and referral may improve prediabetes and diabetes diagnosis. Point of care testing, specifically in dental practices, can play a vital role in the early detection of type 2 diabetes [86]. Many individuals may not seek diabetic testing due to fear. Dental practitioners often have strong, trusting relationships with patients that may help them feel more comfortable discussing health concerns, like diabetes and Alzheimer's. These are incredible opportunities for dental professionals to help in early detection.

\section{Special Note on Medicare}

Having access to dental care is difficult for many US populations especially the elderly and not having access is associated with cognitive decline [87]. It would be kinder and fiscally more responsible to extend Medicare benefits to dentistry if it lowers the cases of a disease projected to affect so many people in such a near future. In 2020, Alzheimer's and other dementias cost the nation $\sim \$ 305$ and $\$ 206$ billion in Medicare and Medicaid payments [2]. If dental care were added to Medicare, it may help to reduce the flood of cases. Unless a treatment to slow, stop or prevent this disease is developed, in 2050, Alzheimer's cost is projected to exceed $\$ 1.1$ trillion. This dramatic rise includes more than 4 -fold increases in government spending under Medicare and Medicaid, and in out-of-pocket spending [2].

Medicare beneficiaries with Alzheimer's regularly have other chronic conditions, such as heart disease, diabetes, and kidney disease, and require more skilled nursing, home health, and hospital stays per year than other older people [2]. Not only are there regulations as to whether dental professionals can even do services in a care facility depending on state governing bodies, but there are minimal state and federal guidelines regarding dental care. The inclusion of dental services in Medicare may help to combat the ravages of Alzheimer's disease and curtail the rapid rise in diagnosis rates.

\section{CONCLUSION}

Successful healthcare is not just the proper management of disease, but it includes strong prevention strategies. Something must be done to spread knowledge on preventive measures to help slow down the rate of Alzheimer's disease. The goal of this perspective piece is to provide examples for the need to bring dentistry into the fold of interdisciplinary approaches in healthcare. The utilization of all healthcare providers is essential along with universal education, partnerships, and healthcare coverage. Many of our communities are left behind due to access and cost and many professionals are not willing to serve those regions. Dental professionals focus on disease prevention, health promotion and often form longterm relationships with their patients. The nature of these relationships can help dental professionals notice subtle changes that may be indicators of a future Alzheimer's diagnosis, and preventative care and education can then be advised. New roles are emerging to help address specific treatment needs and access to dental care, but much more must be done. Many dental hygienists are open to not only expanding services into the underserved communities but working within other healthcare areas such as hospitals and physicians' offices. Including dental care coverage to Medicare would be advantageous but making needed changes will not be easy. Innovative collaborative efforts must be made, and dental professionals are uniquely situated to help roll back the tide of this horrible disease.

For further information you may be interested in attend consensus conferences addressing oral systemic health, collaboration and integration principles. Some examples include, but not limited to, The Santa Fe Group Oral Health into Overall Health https://santafegroup.org/ events/ The American Academy of Oral Systemic Health Collaboration Cures https://www.aaosh.org/2021-scientificsession The Dental Integration Conference A Time That's Come https://www.dentalintegrationconference.com 


\section{DATA AVAILABILITY STATEMENT}

The original contributions presented in the study are included in the article/supplementary material, further inquiries can be directed to the corresponding author/s.

\section{REFERENCES}

1. Encyclopedia of Neuroscience. 1st ed. Available from: https://www.elsevier. com/books/encyclopedia-of-neuroscience/squire/978-0-08-044617-2 (accessed April 7, 2021).

2. Facts and Figures. Alzheimer's Disease and Dementia. Available from: https:// www.alz.org/alzheimers-dementia/facts-figures (accessed February 28, 2021).

3. Alzheimer's Disease a Much Larger Cause of Death Than Previously Recognized. Available from: https://www.rush.edu/news/alzheimers-disease-muchlarger-cause-death-previously-recognized (accessed February 28, 2021).

4. Cummings JL, Morstorf T, Zhong K. Alzheimer's disease drug-development pipeline: few candidates, frequent failures. Alzheimers Res Ther. (2014) 6:37. doi: 10.1186/alzrt269

5. Broom GM, Shaw IC, Rucklidge JJ. The ketogenic diet as a potential treatment and prevention strategy for Alzheimer's disease. Nutrition. (2019) 60:11821. doi: 10.1016/j.nut.2018.10.003

6. Sun B-L, Li W-W, Zhu C, Jin W-S, Zeng F, Liu Y-H, et al. Clinical research on Alzheimer's disease: progress and perspectives. Neurosci Bull. (2018) 34:11118. doi: 10.1007/s12264-018-0249-z

7. Berkowitz CL, Mosconi L, Rahman A, Scheyer O, Hristov H, Isaacson RS. Clinical application of APOE in Alzheimer's prevention: a precision medicine approach. J Prev Alzheimers Dis. (2018) 5:245-52. doi: 10.14283/jpad.2018.35

8. Diabetes and Alzheimer's Disease: Can Tea Phytochemicals Play a Role in Prevention? IOS Press. Available from: https://content.iospress.com/articles/ journal-of-alzheimers-disease/jad161200 (accessed April 6, 2021).

9. Mander BA, Winer JR, Jagust WJ, Walker MP. Sleep: a novel mechanistic pathway, biomarker, and treatment target in the pathology of Alzheimer's disease? Trends Neurosci. (2016) 39:552-66. doi: 10.1016/j.tins.2016.05.002

10. De la Rosa A, Olaso-Gonzalez G, Arc-Chagnaud C, Millan F, SalvadorPascual A, García-Lucerga C, et al. Physical exercise in the prevention and treatment of Alzheimer's disease. J Sport Health Sci. (2020) 9:394404. doi: 10.1016/j.jshs.2020.01.004

11. Livingston G, Huntley J, Sommerlad A, Ames D, Ballard $\mathrm{C}$, Banerjee $\mathrm{S}$, et al. Dementia prevention, intervention, and care: 2020 report of the Lancet Commission. Lancet. (2020) 396:413-46. doi: 10.1016/S0140-6736(20)30367-6

12. WHO. Risk Reduction of Cognitive Decline Dementia. WHO. World Health Organization. Available from: http://www.who.int/mental_health/neurology/ dementia/guidelines_risk_reduction/en/ (accessed February 28, 2021).

13. Lim ASP, Kowgier M, Yu L, Buchman AS, Bennett DA. Sleep fragmentation and the risk of incident alzheimer's disease and cognitive decline in older persons. Sleep. (2013) 36:1027-32. doi: 10.5665/sleep.2802

14. Irwin MR, Vitiello MV. Implications of sleep disturbance and inflammation for Alzheimer's disease dementia. Lancet Neurol. (2019) 18:296-306. doi: 10.1016/S1474-4422(18)30450-2

15. Wennberg AMV, Wu MN, Rosenberg PB, Spira AP. Sleep disturbance, cognitive decline, and dementia: a review. Semin Neurol. (2017) 37:395406. doi: 10.1055/s-0037-1604351

16. Ma Y, Liang L, Zheng F, Shi L, Zhong B, Xie W. Association between sleep duration and cognitive decline. JAMA Netw Open. (2020) 3:e2013573. doi: 10.1001/jamanetworkopen.2020.13573

17. Wang RP-H, Ho Y-S, Leung WK, Goto T, Chang RC-C. Systemic inflammation linking chronic periodontitis to cognitive decline. Brain Behav Immun. (2019) 81:63-73. doi: 10.1016/j.bbi.2019.07.002

18. Matsushita K, Yamada-Furukawa M, Kurosawa M, Shikama Y. Periodontal disease and periodontal disease-related bacteria involved in the pathogenesis of Alzheimer's disease. JIR. (2020) 13:275-83. doi: 10.2147/JIR.S255309

19. Gaur S, Agnihotri R. Alzheimer's disease and chronic periodontitis: is there an association? Geriatr Gerontol Int. (2015) 15:391-404. doi: 10.1111/ggi.12425

\section{AUTHOR CONTRIBUTIONS}

AOR conceived and presented the idea and wrote the perspective article based upon their opinion and data supporting that opinion.

20. Beason-Held LL, Goh JO, An Y, Kraut MA, O’Brien RJ, Ferrucci $\mathrm{L}$, et al. Changes in brain function occur years before the onset of cognitive impairment. J Neurosci. (2013) 33:1800814. doi: 10.1523/JNEUROSCI.1402-13.2013

21. Younes L, Albert M, Moghekar A, Soldan A, Pettigrew C, Miller MI. Identifying changepoints in biomarkers during the preclinical phase of Alzheimer's disease. Front Aging Neurosci. (2019) 11:74. doi: 10.3389/fnagi.2019.00074

22. Kang J, Wu B, Bunce D, Ide M, Aggarwal VR, Pavitt S, et al. Bidirectional relations between cognitive function and oral health in ageing persons: a longitudinal cohort study. Age Ageing. (2020) 49:7939. doi: 10.1093/ageing/afaa025

23. Lamar M, Boots EA, Arfanakis K, Barnes LL, Schneider JA. Common brain structural alterations associated with cardiovascular disease risk factors and Alzheimer's dementia: future directions and implications. Neuropsychol Rev. (2020) 30:546-57. doi: 10.1007/s11065-020-09460-6

24. Song R, Xu H, Dintica CS, Pan K-Y, Qi X, Buchman AS, et al. Associations between cardiovascular risk, structural brain changes, and cognitive decline. $J$ Am Coll Cardiol. (2020) 75:2525-34. doi: 10.1016/j.jacc.2020.03.053

25. Anjum I, Fayyaz M, Wajid A, Sohail W, Ali A. Does obesity increase the risk of dementia: a literature review. Cureus. (2018) 10. doi: 10.7759/cureus.2660

26. Lennon MJ, Koncz R, Sachdev PS. Hypertension and Alzheimer's disease: is the picture any clearer? Curr Opin Psychiatry. (2021) 34:142-8. doi: 10.1097/YCO.0000000000000684

27. Sáiz-Vazquez O, Puente-Martínez A, Ubillos-Landa S, Pacheco-Bonrostro J, Santabárbara J. Cholesterol and Alzheimer's Disease risk: a meta-metaAnalysis. Brain Sci. (2020) 10:386. doi: 10.3390/brainsci10060386

28. Walker KA, Sharrett AR, Wu A, Schneider ALC, Albert M, Lutsey PL, et al. Association of midlife to late-life blood pressure patterns with incident dementia. JAMA. (2019) 322:535. doi: 10.1001/jama.2019.10575

29. Walker KA, Power MC, Gottesman RF. Defining the relationship between hypertension, cognitive decline, and dementia: a review. Curr Hypertens Rep. (2017) 19:24. doi: 10.1007/s11906-017-0724-3

30. Lane CA, Barnes J, Nicholas JM, Sudre CH, Cash DM, Parker TD, et al. Associations between blood pressure across adulthood and late-life brain structure and pathology in the neuroscience substudy of the 1946 British birth cohort (Insight 46): an epidemiological study. Lancet Neurol. (2019) 18:942-52. doi: 10.1016/S1474-4422(19)30228-5

31. Friedlander AH, Friedlander IK. Identification of stroke prone patients by panoramic radiography. Aust Dent J. (1998) 43:514. doi: 10.1111/j.1834-7819.1998.tb00153.x

32. Kuzma E, Lourida I, Moore SF, Levine DA, Ukoumunne OC, Llewellyn DJ. Stroke and dementia risk: a systematic review and meta-analysis. Alzheimers Dement. (2018) 14:1416-26. doi: 10.1016/j.jalz.2018. 06.3061

33. Vijayan M, Reddy PH. Stroke and vascular dementia and Alzheimer's disease molecular links. J Alzheimers Dis. (2016) 54:427-43. doi: 10.3233/JAD-160527

34. Paju S, Pietiäinen M, Liljestrand JM, Lahdentausta L, Salminen A, Kopra E, et al. Carotid artery calcification in panoramic radiographs associates with oral infections and mortality. Int Endodon J. (2021) 54:1525. doi: 10.1111/iej.13451

35. Hanlon CA, Owens MM, Joseph JE, Zhu X, George MS, Brady KT, et al. Lower subcortical gray matter volume in both younger smokers and established smokers relative to non-smokers. Addict Biol. (2016) 21:18595. doi: 10.1111/adb.12171

36. CDC Tobacco Free. Fast Facts. Atlanta, GA: Centers for Disease Control and Prevention (2020). Available from: https://www.cdc.gov/tobacco/data statistics/fact_sheets/fast_facts/index.htm; https://www.cdc.gov/tobacco/ data_statistics/fact_sheets/fast_facts/index.htm (accessed February 28, 2021). 
37. Liu Y, Li H, Wang J, Xue Q, Yang X, Kang Y, et al. Association of cigarette smoking with cerebrospinal fluid biomarkers of neurodegeneration, neuroinflammation, and oxidation. JAMA Netw Open. (2020) 3:e2018777. doi: 10.1001/jamanetworkopen.2020.18777

38. Five Major Steps to Intervention (The " 5 A's"). Available from: http://www.ahrq. gov/prevention/guidelines/tobacco/5steps.html (accessed February 28, 2021).

39. Institute of Medicine (US) Committee on Sleep Medicine and Research. Sleep disorders and sleep deprivation: an unmet public health problem. In: Colten HR, Altevogt BM, editors. The National Academies Collection: Reports funded by National Institutes of Health. Washington, DC: National Academies Press (2006). Available from: http://www.ncbi.nlm.nih.gov/books/NBK19960/ (accessed April 6, 2021).

40. Wang Y-H, Wang J, Chen S-H, Li J-Q, Lu Q-D, Vitiello MV, et al. Association of longitudinal patterns of habitual sleep duration with risk of cardiovascular events and all-cause mortality. JAMA Netw Open. (2020) 3:e205246. doi: 10.1001/jamanetworkopen.2020.5246

41. Gordleeva S, Kanakov O, Ivanchenko M, Zaikin A, Franceschi C. Brain aging and garbage cleaning : modelling the role of sleep, glymphatic system, and microglia senescence in the propagation of inflammaging. Semin Immunopathol. (2020) 42:647-65. doi: 10.1007/s00281-020-00816-X

42. Nedergaard M, Goldman SA. Glymphatic failure as a final common pathway to dementia. Science. (2020) 370:50-6. doi: 10.1126/science.abb8739

43. Rasch B, Born J. About sleep's role in memory. Physiol Rev. (2013) 93:681766. doi: 10.1152/physrev.00032.2012

44. Xie L, Kang H, Xu Q, Chen MJ, Liao Y, Thiyagarajan M, et al. Sleep drives metabolite clearance from the adult brain. Science. (2013) 342:373-7. doi: 10.1126/science.1241224

45. Spira AP, Gamaldo AA, An Y, Wu MN, Simonsick EM, Bilgel M, et al. Selfreported sleep and $\beta$-amyloid deposition in community-dwelling older adults. JAMA Neurol. (2013) 70:1537-43. doi: 10.1001/jamaneurol.2013.4258

46. Winer JR, Mander BA, Kumar S, Reed M, Baker SL, Jagust WJ, et al. Sleep disturbance forecasts $\beta$-amyloid accumulation across subsequent years. Curr Biol. (2020) 30:4291-4298.e3. doi: 10.1016/j.cub.2020.08.017

47. Lucey BP, McCullough A, Landsness EC, Toedebusch CD, McLeland JS, Zaza $\mathrm{AM}$, et al. Reduced non-rapid eye movement sleep is associated with tau pathology in early Alzheimer's disease. Sci Transl Med. (2019) 11:eaau6550. doi: 10.1126/scitranslmed.aau6550

48. Liguori C, Maestri M, Spanetta M, Placidi F, Bonanni E, Mercuri NB, et al. Sleep-disordered breathing and the risk of Alzheimer's disease. Sleep Med Rev. (2021) 55:101375. doi: 10.1016/j.smrv.2020.101375

49. Tsai M-S, Li H-Y, Huang C-G, Wang RYL, Chuang L-P, Chen N-H, et al. Risk of Alzheimer's disease in obstructive sleep apnea patients with or without treatment: real-world evidence. Laryngoscope. (2020) 130:22928. doi: 10.1002/lary.28558

50. Sleep Apnea Information for Clinicians. sleepapnea.org. Available from: https://www.sleepapnea.org/learn/sleep-apnea-information-clinicians/ (accessed February 28, 2021).

51. Maggard MD, Cascella M. Upper airway resistance syndrome. In: StatPearls. Treasure Island, FL: StatPearls Publishing (2021). Available from: http://www. ncbi.nlm.nih.gov/books/NBK564402/ (accessed April 7, 2021).

52. Francis CE, Quinnell T. Mandibular advancement devices for OSA: an alternative to CPAP? Pulm Ther. (2020) 7:2536. doi: 10.1007/s41030-020-00137-2

53. Schroeder K, Gurenlian JR. Recognizing poor sleep quality factors during oral health evaluations. Clin Med Res. (2019) 17:20-8. doi: 10.3121/cmr.2019.1465

54. Richards KC, Gooneratne N, Dicicco B, Hanlon A, Moelter S, Onen F, et al. CPAP adherence may slow 1-year cognitive decline in older adults with mild cognitive impairment and apnea. J Am Geriatr Soc. (2019) 67:55864. doi: 10.1111/jgs. 15758

55. Bubu OM, Andrade AG, Umasabor-Bubu OQ, Hogan MM, Turner AD, de Leon MJ, et al. Obstructive sleep apnea, cognition and Alzheimer's disease: a systematic review integrating three decades of multidisciplinary research. Sleep Med Rev. (2020) 50:101250. doi: 10.1016/j.smrv.2019.101250

56. Kleinstein SE, Nelson KE, Freire M. Inflammatory networks linking oral microbiome with systemic health and disease. J Dent Res. (2020) 99:11319. doi: $10.1177 / 0022034520926126$

57. Leira Y, Domínguez C, Seoane J, Seoane-Romero J, Pías-Peleteiro JM, Takkouche B, et al. Is periodontal disease associated with Alzheimer's disease?
A systematic review with meta-analysis. Neuroepidemiology. (2017) 48:2131. doi: 10.1159/000458411

58. Dominy SS, Lynch C, Ermini F, Benedyk M, Marczyk A, Konradi A, et al. Porphyromonas gingivalis in Alzheimer's disease brains: evidence for disease causation and treatment with small-molecule inhibitors. Sci Adv. (2019) 5:eaau3333. doi: 10.1126/sciadv.aau3333

59. Oueslati Y, Oualha L, Touil D. Periodontal Disease and its Relevance in the Etiopathogenesis of Alzheimer's disease: A Systematic Review. In: 2018 Tunisian Annual Meeting. Monastir: EC Dental Science (2019).

60. Tonsekar PP, Jiang SS, Yue G. Periodontal disease, tooth loss and dementia: is there a link? A systematic review. Gerodontology. (2017) 34:15163. doi: 10.1111/ger.12261

61. Beydoun MA, Beydoun HA, Hossain S, El-Hajj ZW, Weiss J, Zonderman $\mathrm{AB}$. Clinical and bacterial markers of periodontitis and their association with incident all-cause and Alzheimer's disease dementia in a Large National Survey. J Alzheimers Dis. (2020) 75:157-72. doi: 10.3233/JAD-200064

62. Piacentini R, De Chiara G, Li Puma DD, Ripoli C, Marcocci ME, Garaci E, et al. HSV-1 and Alzheimer's disease: more than a hypothesis. Front Pharmacol. (2014) 5:97. doi: 10.3389/fphar.2014.00097

63. Dioguardi M, Crincoli V, Laino L, Alovisi M, Sovereto D, Mastrangelo F, et al. The role of periodontitis and periodontal bacteria in the onset and progression of Alzheimer's disease: a systematic review. J Clin Med. (2020) 9:495. doi: 10.3390/jcm9020495

64. Wadhawan A, Reynolds MA, Makkar H, Scott AJ, Potocki E, Hoisington AJ, et al. Periodontal pathogens and neuropsychiatric health. Curr Top Med Chem. (2020) 20:1353-97. doi: 10.2174/1568026620666200110161105

65. Miklossy J. Alzheimer's disease - a neurospirochetosis. Analysis of the evidence following Koch's and Hill's criteria. J Neuroinflamm. (2011) 8:90. doi: 10.1186/1742-2094-8-90

66. Su X, Tang Z, Lu Z, Liu Y, He W, Jiang J, et al. Oral treponema denticola infection induces $A \beta 1-40$ and $A \beta 1-42$ accumulation in the hippocampus of C57BL/6 mice. J Mol Neurosci. (2021). doi: 10.21203/rs.3.rs-225008/v1. [Epub ahead of print].

67. Eimer WA, Vijaya Kumar DK, Navalpur Shanmugam NK, Rodriguez AS, Mitchell T, Washicosky KJ, et al. Alzheimer's disease-associated $\beta$-amyloid is rapidly seeded by herpesviridae to protect against brain infection. Neuron (2018) 99:56-63.e3. doi: 10.1016/j.neuron.2018.06.030

68. Soscia SJ, Kirby JE, Washicosky KJ, Tucker SM, Ingelsson M, Hyman B, et al. The Alzheimer's disease-associated amyloid $\beta$-protein is an antimicrobial peptide. PLoS ONE. (2010) 5:e9505. doi: 10.1371/journal.pone.0009505

69. Carter CJ. Genetic, transcriptome, proteomic, and epidemiological evidence for blood-brain barrier disruption and polymicrobial brain invasion as determinant factors in Alzheimer's disease. J Alzheimer Dis Rep. (2017) 1:12557. doi: 10.3233/ADR-170017

70. Fang P, Kazmi SA, Jameson KG, Hsiao EY. The microbiome as a modifier of neurodegenerative disease risk. Cell Host Microbe. (2020) 28:20122. doi: 10.1016/j.chom.2020.06.008

71. Sochocka M, Zwolińska K, Leszek J. The infectious etiology of Alzheimer's disease. Curr Neuropharmacol. (2017) 15:9961009. doi: 10.2174/1570159X15666170313122937

72. Holt SC, Ebersole JL. Porphyromonas gingivalis, Treponema denticola, and Tannerella forsythia: the "red complex", a prototype polybacterial pathogenic consortium in periodontitis. Periodontol 2000. (2005) 38:72122. doi: 10.1111/j.1600-0757.2005.00113.x

73. Olsen I, Taubman MA, Singhrao SK. Porphyromonas gingivalis suppresses adaptive immunity in periodontitis, atherosclerosis, and Alzheimer's disease. J Oral Microbiol. (2016) 8:1. doi: 10.3402/jom.v8.33029

74. Costa MJF, de Araújo IDT, da Rocha Alves L, da Silva RL, Dos Santos Calderon P, Borges BCD, et al. Relationship of Porphyromonas gingivalis and Alzheimer's disease: a systematic review of pre-clinical studies. Clin Oral Investig. (2021) 25:797-806. doi: 10.1007/s00784-02003764-w

75. Kanagasingam S, Chukkapalli SS, Welbury R, Singhrao SK. Porphyromonas gingivalis is a strong risk factor for Alzheimer's disease. J Alzheimers Dis Rep. (2020) 4:501-11. doi: 10.3233/ADR-200250

76. Genco RJ, Sanz M. Clinical and public health implications of periodontal and systemic diseases: an overview. Periodontol 2000. (2020) 83:713. doi: $10.1111 /$ prd. 12344 
77. Hajishengallis G, Chavakis T. Local and systemic mechanisms linking periodontal disease and inflammatory comorbidities. Nat Rev Immunol. (2021) 1-15. doi: 10.1038/s41577-020-00488-6. [Epub ahead of print].

78. Kitamoto S, Nagao-Kitamoto H, Jiao Y, Gillilland MG, Hayashi A, Imai J, et al. The intermucosal connection between the mouth and gut in commensal pathobiont-driven colitis. Cell. (2020) 182:447-62.e14. doi: 10.1016/j.cell.2020.05.048

79. Marizzoni M, Cattaneo A, Mirabelli P, Festari C, Lopizzo N, Nicolosi V, et al. Short-chain fatty acids and lipopolysaccharide as mediators between gut dysbiosis and amyloid pathology in Alzheimer's disease. J Alzheimers Dis. (2020) 78:683-97. doi: 10.3233/JAD-200306

80. Aguilar M, Bhuket $\mathrm{T}$, Torres S, Liu B, Wong RJ. Prevalence of the metabolic syndrome in the United States, 20032012. JAMA. (2015) 313:1973. doi: 10.1001/jama.2015. 4260

81. Khan MSH, Hegde V. Obesity and diabetes mediated chronic inflammation: a potential biomarker in Alzheimer's Disease. J Pers Med. (2020) 10:42. doi: 10.3390/jpm10020042

82. Stanciu GD, Bild V, Ababei DC, Rusu RN, Cobzaru A, Paduraru L, et al. Link between diabetes and Alzheimer's disease due to the shared amyloid aggregation and deposition involving both neurodegenerative changes and neurovascular damages. J Clin Med. (2020) 9:1713. doi: 10.3390/jcm9061713

83. Researchers Link Alzheimer's Gene to Type 3 Diabetes. Available form: https://newsnetwork.mayoclinic.org/; https://newsnetwork.mayoclinic.org/ discussion/researchers-link-alzheimers-gene-to-type-iii-diabetes/ (accessed February 28, 2021).

84. Panza F, Frisardi V, Seripa D, P Imbimbo B, Sancarlo D, D'Onofrio G, et al. Metabolic Syndrome, Mild Cognitive Impairment and Dementia. Curr Alzheimer Res. (2011) 8:492-509. doi: 10.2174/156720511796391818

85. Zheng F, Yan L, Yang Z, Zhong B, Xie W. HbAlc, diabetes and cognitive decline: the english longitudinal study of ageing. Diabetologia. (2018) 61:83948. doi: 10.1007/s00125-017-4541-7

86. Montero E, Matesanz P, Nobili A, Luis Herrera-Pombo J, Sanz M, Guerrero A, et al. Screening of undiagnosed hyperglycaemia in the dental setting: the DiabetRisk study. A field trial. J Clin Periodontol. (2021) 48:37888. doi: $10.1111 /$ jcpe. 13408

87. Han SH, Wu B, Burr JA. Edentulism and trajectories of cognitive functioning among older adults: the role of dental care service utilization. J Aging Health. (2020) 32:744-52. doi: 10.1177/0898264319851654

Conflict of Interest: AOR is the owner of company Oral Systemic Seminars.

Copyright $\odot 2021$ Rice. This is an open-access article distributed under the terms of the Creative Commons Attribution License (CC BY). The use, distribution or reproduction in other forums is permitted, provided the original author(s) and the copyright owner(s) are credited and that the original publication in this journal is cited, in accordance with accepted academic practice. No use, distribution or reproduction is permitted which does not comply with these terms. 